\title{
FOREWORD (1994)
}

\section{Walter Murch}

We gestate in Sound, and are born into Sight Cinema gestated in Sight, and was born into Sound.

W

E BEGIN to hear before we are born, four and a half months after conception. From then on, we develop in a continuous and luxurious bath of sounds: the song of our mother's voice, the swash of her breathing, the trumpeting of her intestines, the timpani of her heart. Throughout the second four-and-a-half months, Sound rules as solitary Queen of our senses: the close and liquid world of uterine darkness makes Sight and Smell impossible, Taste monochromatic, and Touch a dim and generalized hint of what is to come.

Birth brings with it the sudden and simultaneous ignition of the other four senses, and an intense competition for the throne that Sound had claimed as hers. The most notable pretender is the darting and insistent Sight, who dubs himself King as if the throne had been standing vacant, waiting for him.

Ever discreet, Sound pulls a veil of oblivion across her reign and withdraws into the shadows, keeping a watchful eye on the braggart Sight. If she gives up her throne, it is doubtful that she gives up her crown.

In a mechanistic reversal of this biological sequence, Cinema spent its youth (1892-1927) wandering in a mirrored hall of voiceless images, a 
thirty-five year bachelorhood over which Sight ruled as self-satisfied, solipsistic King-never suspecting that destiny was preparing an arranged marriage with the Queen he thought he had deposed at birth.

This cinematic inversion of the natural order may be one of the reasons that the analysis of sound in films has always been peculiarly elusive and problematical, if it was attempted at all. In fact, despite her dramatic entrance in 1927 , Queen Sound has glided around the hall mostly ignored even as she has served us up her delights, while we continue to applaud King Sight on his throne. If we do notice her consciously, it is often only because of some problem or defect.

Such self-effacement seems at first paradoxical, given the power of sound and the undeniable technical progress it has made in the last sixty-five years. A further examination of the source of this power, however, reveals it to come in large part from the very handmaidenly quality of self-effacement itself: by means of some mysterious perceptual alchemy, whatever virtues sound brings to the film are largely perceived and appreciated by the audience in visual terms - the better the sound, the better the image. The French composer, filmmaker, and theoretician Michel Chion has dedicated a large part of Audio-Vision to drawing out the various aspects of this phenomenon-which he terms added value - and this alchemy also lies at the heart of his three earlier, asyet-untranslated works on film sound: Le Son au cinéma, La Voix au cinéma, and La Toile trouée. It gives me great pleasure to be able to introduce this author to the American public, and I hope it will not be long before his other works are also translated and published.

It is symptomatic of the elusive and shadowy nature of film sound that Chion's four books stand relatively alone in the landscape of film criticism, representing as they do a significant portion of everything that has ever been published about film sound from a theoretical point of view. For it is also part of Sound's effacement that she respectfully declines to be interviewed, and previous writers on film have with uncharacteristic circumspection largely respected her wishes.

It is also characteristic that this silence has been broken by a European rather than an American-even though sound for films was an American invention, and nearly all of the subsequent developments (including the most recent Dolby SR-D digital soundtrack) have been American or Anglo-American. As fish are the last to become aware of 
the water in which they swim, Americans take their sound for granted. But such was-and is-not the case in Europe, where the invasion of sound from across the Atlantic in 1927 was decidedly a mixed blessing and something of a curse: not without reason is chapter 7 of AudioVision (on the arrival of sound) ironically subheaded "Sixty Years of Regrets."

There are several reasons for Europe's ambivalent reaction to film sound, but the heart of the problem was foreshadowed by Faust in 1832, when Goethe had him proclaim:

It is written that in the Beginning was the Word!

$\mathrm{Hmm}$... already I am having problems.

The early sound films were preeminently talking films, and the Word - with all of the power that language has to divide nation from nation as well as conquer individual hearts-has long been both the Achilles' heel of Europe as well as its crowning glory. In 1927 there were over twenty different languages spoken in Europe by two hundred million people in twenty-five different, highly developed countries. Not to mention different dialects and accents within each language and a number of countries such as Switzerland and Belgium that are multilingual.

Silent films, however, which blossomed during and after the First World War, were Edenically oblivious of the divisive powers of the Word, and were thus able - when they so desired-to speak to Europe as a whole. It is true that most of these films had intertitle cards, but these were easily and routinely switched according to the language of the country in which the film was being shown.

Even so, title cards were generally discounted as a necessary evil and there were some films, like those of writer Carl Mayer (The Last Laugh), that managed to tell their story without any cards at all and were highly esteemed for this ability, which was seen as the wave of the future.

It is also worth recalling that at that time the largest studio in Europe was Nordisk Films in Denmark, a country whose population of two million souls spoke a language understood nowhere else. And Asta Nielsen, the Danish star who made many films for Ufa Studios in Germany, was beloved equally by French and German soldiers during the 
1914-18 war-her picture decorated the trenches on both sides. It is doubtful that the French poet Apollinaire, if he had heard her speaking in German, would have written his ode to her-

\section{She is all!}

She is the vision of the drinker and the dream of the lonely man!

-but since she hovered in shimmering and enigmatic silence, the dreaming soldiers could imagine her speaking any language they wished and make of her their sister or their lover according to their needs.

So the hopeful spirit of the League of Nations, which flourished for a while after the War That Was Supposed to End All Wars, seemed to be especially served by many of the films of the period, which-in their creative struggle to overcome the disability of silence-rose above the particular and spoke to those aspects of the human condition that know no national boundaries: Chaplin was adopted as a native son by each of the countries in which his films were shown. Some optimists even dared to think of film as a providential tool delivered in the nick of time to help unite humanity in peace: a new, less material tower erected by a modern Babel. The main studios of Ufa in Germany were in fact located in a suburb of Berlin named Neubabelsberg (new Babel city).

Thus it was with a sense of queasy foreboding that many film lovers in Europe heard the approaching drumbeat of Sound. Chaplin held out, resisting a full soundtrack for his films until—significantly-The Great Dictator (1938). As it acquired a voice, the Tool for Peace began more to resemble the Gravedigger's Spade that had helped to dig the trenches of nationalist strife.

There were of course many more significant reasons for the rise of the Great Dictators in the twenties and thirties, and it is true that the silent film had sometimes been used to rally people around the flag, but it is nonetheless chilling to recall that Hitler's ascension to power marched in lockstep with the successful development of the talking film. And, of course, precisely because it did emphasize language, the sound film dovetailed with the divisive nationalist agendas of Hitler, Stalin, Mussolini, Franco, and others. Hitler's first public act after his 
victory in 1933 was to attend a screening of Dawn, a sound film about the German side of the 1914-18 conflict, in which one of the soldiers says, "Perhaps we Germans do not know how to live; but to die, that we know how to do incredibly well."

Alongside these political implications, the coming of sound allowed the American studios to increase their economic presence in Europe and accelerated the flight of the most talented and promising continental filmmakers (Lubitsch, Lang, Freund, Wilder, Zinnemann, etc.) to distant Hollywood. Neubabelsberg suffered the same fate as its Biblical namesake. To further sour the marriage, the first efforts at sound itself were technically poor, unimaginative, and expensive- the result of American patents that had to be purchased. Early sound recording apparatus also straitjacketed the camera and consequently impoverished the visual richness and fluidity that had been attained in the mature films of the silent era. Nordisk Films collapsed. The studios that were left standing, facing rising production costs and no longer able to count on a market outside the borders of their own country, had to accept some form of government assistance to survive, with all that such assistance implies. Studios in the United States, on the other hand, were insulated by an eager domestic audience three times the size of the largest single European market, all conveniently speaking the same language. As the United States was spared the bloodshed on its soil in both world wars, it was spared the conflict of the sound wars and, in fact, managed to profit by them.

Sixty-five years later, the reverberations of this political, cultural, and economic trauma still echo throughout Europe in an unsettled critical attitude toward film sound - and a multitude of aesthetic approachesthat have no equivalent in the United States: compare Chion's description of the French passion for "location" sound at all costs (Eric Rohmer) with the Italian reluctance to use it under any circumstances (Fellini). This is not to say that Chion, as a European, shares the previously mentioned regrets-just the opposite: he is an ardent admirer and proponent of soundtracks from both sides of the Atlantic-but as a European he is naturally more sensitive to the economic, cultural, political, and aesthetic ramifications of the marriage of Sight and Sound. And since the initial audience for his books and articles has also-until now-been European, part of his task has been to convince his wary 
continental readers of the artistic merits of film sound (the French word for sound effect, for instance, is bruit-which translates as "noise," with all of the same pejorative overtones that the word has in English) and to persuade them to forgive Sound the guilt by association of having been present at the bursting of the silent film's illusory bubble of peace. American readers of this book should therefore be aware that they are-in part-eavesdropping on the latest stage of a family discussion that has been simmering in Europe, with various degrees of acrimony, since the marriage of Sight and Sound was consummated in 1927.

Yet a European perspective does not, by itself, yield a book like AudioVision: Chion's efforts to explore and synthesize a comprehensive theory of film sound-rather than polemicize it-are largely unprecedented even in Europe. There is another aspect to all this, which the following story might illuminate.

In the early 1950s, when I was around ten years old, and inexpensive magnetic tape recorders were first becoming available, I heard a rumor that the father of a neighborhood friend had actually acquired one. Over the next few months, I made a pest of myself at that household, showing up with a variety of excuses just to be allowed to play with that miraculous machine: hanging the microphone out the window and capturing the back-alley reverberations of Manhattan, Scotch taping it to the shaft of a swing-arm lamp and rapping the bell-shaped shade with pencils, inserting it into one end of a vacuum cleaner tube and shouting into the other, and so forth.

Later on, I managed to convince my parents of all the money our family would save on records if we bought our own tape recorder and used it to "pirate" music off the radio. I now doubt that they believed this made any economic sense, but they could hear the passion in my voice, and a Revere recorder became that year's family Christmas present.

I swiftly appropriated the machine into my room and started banging on lamps again and resplicing my recordings in different, more exotic combinations. I was in heaven, but since no one else I knew shared this vision of paradise, a secret doubt about myself began to worm its way into my preadolescent thoughts. 
One evening, though, I returned home from school, turned on the radio in the middle of a program, and couldn't believe my ears: sounds were being broadcast the likes of which I had only heard in the secrecy of my own little laboratory. As quickly as possible, I connected the recorder to the radio and sat there listening, rapt, as the reels turned and the sounds became increasingly strange and wonderful.

It turned out to be the Premier Panorama de Musique Concrète, a record by the French composers Pierre Schaeffer and Pierre Henry, and the incomplete tape of it became a sort of Bible of Sound for me. Or rather a Rosetta stone, because the vibrations chiseled into its iron oxide were the mysteriously significant and powerful hieroglyphs of a language that I did not yet understand but whose voice nonetheless spoke to me compellingly. And above all told me that I was not alone in my endeavors.

Those preadolescent years that I spent pickling myself in my jar of sound, listening and recording and splicing without reference to any image, allowed me-when I eventually came to film - to see through Sound's handmaidenly self-effacement and catch more than a glimpse of her crown.

I mention this fragment of autobiography because apparently Michel Chion came to his interest in film sound through a similar sequence of events. Such a "biological" approach-sound first, image laterstands in contrast not only to the way most people approach filmimage first, sound later-but, as we have seen, to the history of cinema itself. As it turns out, Chion is a brother not only in this but also in having Schaeffer and Henry as mentors (although he has the privilege, which I lack, of a long-standing personal contact with those composers), and I was happy to see Schaeffer's name and some of his theories woven into the fabric of Audio-Vision. At any rate, I suspect that a primary emphasis on sound for its own sake-combined in Chion's case with a European perspective-must have provided the right mixture of elements to inspire him to knock on reclusive Sound's door, and to see his suitor's determination rewarded with armfuls of intimate details.

What had conquered me in 1953, what had conquered Schaeffer and Henry some years earlier, and what was to conquer Chion in turn was 
not just the considerable power of magnetic tape to capture ordinary sounds and reorganize them-optical film and discs had already had something of this ability for decades-but the fact that the tape recorder combined these qualities with full audio fidelity, low surface noise, unrivaled accessibility, and operational simplicity. The earlier forms of sound recording had been expensive, available to only a few people outside the laboratory or studio situations, noisy and deficient in their frequency range, and cumbersome and awkward to operate. The tape recorder, on the other hand, encouraged play and experimentation, and that was-and remains-its preeminent virtue.

For as far back in human history as you would care to go, sounds had seemed to be the inevitable and "accidental" (and therefore mostly ignored) accompaniment of the visual—stuck like a shadow to the object that caused them. And, like a shadow, they appeared to be completely explained by reference to the objects that gave them birth: a metallic clang was always "cast" by the hammer, just as the smell of baking always came from a loaf of fresh bread.

Recording magically lifted the shadow away from the object and stood it on its own, giving it a miraculous and sometimes frightening substantiality. King Ndombe of the Congo consented to have his voice recorded in 1904, but immediately regretted it when the cylinder was played back and the "shadow" danced, and he heard his people cry in dismay, "The King sits still, his lips are sealed, while the white man forces his soul to sing!"

The tape recorder extended this magic by an order of magnitude, and made it supremely democratic in the bargain, such that a ten-year-old boy like myself could think of it as a wonderful toy. Furthermore, it was now not only possible but easy to change the original sequence of the recorded sounds, speed them up, slow them down, play them backward. Once the shadow of sound had learned to dance, we found ourselves able to not only listen to the sounds themselves, liberated from their original causal connection, and to layer them in new, formerly impossible recombinations (musique concrète) but also-in cinema-to reassociate those sounds with images of objects or situations that were different, sometimes astonishingly different, than the objects or situations that gave birth to the sounds in the first place.

And here is the problem: the shadow that had heretofore either been ignored or consigned to follow along submissively behind the image 
was suddenly running free, or attaching itself mischievously to the unlikeliest things. And our culture, which is not an "auditive" one, had never developed the concepts or language to adequately describe or cope with such an unlikely challenge from such a mercurial force-as Chion points out: "There is always something about sound that bypasses and surprises us, no matter what we do." In retrospect, it is no wonder that few have dared to confront the dancing shadow and the singing soul: it is this deficiency that Michel Chion's Audio-Vision bravely sets out to rectify.

The essential first step that Chion takes is to assume that there is no "natural and preexisting harmony between image and sound"that the shadow is in fact dancing free. In his usual succinct manner, Robert Bresson captured the same idea: "Images and sounds, like strangers who make acquaintance on a journey and afterwards cannot separate."

The challenge that an idea like this presents to the filmmaker is how to create the right situations and make the right choices so that bonds of seeming inevitability are forged between the film's images and sounds, while admitting that there was nothing inevitable about them to begin with. The "journey" is the film, and the particular "acquaintance" lasts within the context of that film: it did not preexist and is perfectly free to be reformed differently on subsequent trips.

The challenge to a theoretician like Chion, on the other hand, is how to define-as broadly but as precisely as possible-the circumstances under which the "acquaintance" can be made, has been made in the past, and might best be made in the future. This challenge Chion takes up in the first six chapters of Audio-Vision in the form of an "Audiovisual Contract"-a synthesis and further extension of the theories developed over the last ten years in his previous three books. I should mention that as a result this section has a structural and conceptual density that may require closer attention than the second part (chapters 7-10: "Beyond Sounds and Images"), which is more freely discursive.

In the course of drawing up his contract, Chion quickly runs into the limits of ordinary language (English as well as French) to describe certain aspects of sound. This is to be expected, given the fact that we are trying to trap a shadow behind the bars of a contract, but in the process Chion forges a number of original words that give him at least a fighting chance: synchresis, spatial magnetization, acousmatic sound, 
reduced listening, rendered sound, sound "en creux," the phantom of the Acousmêtre, and so on-even audio-vision itself, which acquires a new meaning beyond the obvious.

Some of these terms represent concepts that will be familiar to those of us who work in film sound, but which we have either never had to articulate or for which we have developed our own individual shorthand-or for which we resort to grunts and gestures. It was a pleasure to see these old friends dressed up in new clothes, so to speak, and to have the opportunity to reevaluate them free of old or unstated assumptions. By the same token, other of Chion's ideas are, for me, completely new and original ways of thinking about the subject-in that regard I was particularly impressed by the concept of the "Acousmêtre." But the real achievement of Audio-Vision is-beyond simply naming and describing these isolated ideas and concepts-that it manages to synthesize them into a coherent whole whose overall pattern makes it accessible to interested nonprofessionals as well as those who have experience in the craft.

We take it for granted that this dancing shadow of sound, once free of the object that created it, can then reattach itself to a wide range of other objects and images. The sound of an ax chopping wood, for instance, played exactly in sync with a bat hitting a baseball, will "read" as a particularly forceful hit rather than a mistake by the filmmakers. Chion's term for this phenomenon is synchresis, an acronym formed by the telescoping together of the two words synchronism and synthesis: "The spontaneous and irresistible mental fusion, completely free of any logic, that happens between a sound and a visual when these occur at exactly the same time."

It might have been otherwise - the human mind could have demanded absolute obedience to "the truth"-but for a range of practical and aesthetic reasons we are lucky that it didn't: the possibility of reassociation of image and sound is the fundamental stone upon which the rest of the edifice of film sound is built, and without which it would collapse.

This reassociation is done for many reasons: sometimes in the interests of making a sound appear more "real" than reality (what Chion calls rendered sound) —walking on cornstarch, for instance, records as a better footstep in snow than snow itself; sometimes it is done simply 
for convenience (cornstarch, again) or necessity - the window that Gary Cooper broke in High Noon was not made of real glass, the boulder that chased Indiana Jones was not made of real stone, or morality - the sound of a watermelon being crushed instead of a human head. In each case, our species' multimillion-year habit of thinking of sound as a submissive shadow now works in a filmmaker's favor, and the audience is disposed to accept, within certain limits, these new juxtapositions as the truth.

But beyond all practical considerations, this reassociation is doneshould be done, I believe-to stretch the relationship of sound to image wherever possible: to create a purposeful and fruitful tension between what is on the screen and what is kindled in the mind of the audience-what Chion calls sound en creux (sound "in the gap"). The danger of present-day cinema is that it can crush its subjects by its very ability to represent them; it doesn't possess the built-in escape valves of ambiguity that painting, music, literature, radio drama, and blackand-white silent film automatically have simply by virtue of their sensory incompleteness - an incompleteness that engages the imagination of the viewer as compensation for what is only evoked by the artist. By comparison, film seems to be "all there" (it isn't, but it seems to be), and thus the responsibility of filmmakers is to find ways within that completeness to refrain from achieving it. To that end, the metaphoric use of sound is one of the most fruitful, flexible, and inexpensive means: by choosing carefully what to eliminate, and then reassociating different sounds that seem at first hearing to be somewhat at odds with the accompanying image, the filmmaker can open up a perceptual vacuum into which the mind of the audience must inevitably rush.

It is this movement "into the vacuum" (or "into the gap," to use Chion's phrase) that is in all probability the source of the added value mentioned earlier. Every successful metaphor-what Aristotle called "naming a thing with that which is not its name"-is seen initially and briefly as a mistake, but then suddenly as a deeper truth about the thing named and our relationship to it. And the greater the metaphoric distance, or gap, between image and accompanying sound, the greater the value added-within certain limits. The slippery thing in all this is that there seems to be a peculiar "stealthy" quality to this added value: it chooses not to acknowledge its origins in the mind. 
The tension produced by the metaphoric distance between sound and image serves somewhat the same purpose, creatively, as the perceptual tension produced by the physical distance between our two eyes-a three-inch gap that yields two similar but slightly different images: one produced by the left eye and the other by the right. The brain is not content with this close duality and searches for something that would resolve and unify those differences. And it finds it in the concept of depth. By adding its own purely mental version of threedimensionality to the two flat images, the brain causes them to click together into one image with depth added. In other words, the brain resolves the differences between the two images by imagining a dimensionality that is not actually present in either image but added as the result of a mind trying to resolve the differences between them. As before, the greater the differences, the greater the depth. (Again, within certain limits: cross your eyes-exaggerating the differences-and you will deliver images to the brain that are beyond its power to resolve, and so it passes on to you, by default, a confusing double image. Close one eye-eliminate the differences-and the brain will give you a flat image with no confusion, but also with no value added.)

There really is of course some kind of depth out there in the world: the dimensionality we perceive is not a hallucination. But the way we perceive it-its particular flavor-is uniquely our own, unique not only to us as a species but to each of us individually. And in that sense it $i s$ a kind of hallucination, because the brain does not alert us to the process: it does not announce, "And now I am going to add a helpful dimensionality to synthesize these two flat images. Don't be alarmed." Instead, the dimensionality is fused into the image and made to seem as if it is coming from out there rather than "in here."

In much the same way, the mental effort of fusing image and sound in a film produces a "dimensionality" that the mind projects back onto the image as if it had come from the image in the first place. The result is that we see something on the screen that exists only in our minds, and is in its finer details unique to each member of the audience. It reminds me of John Huston's observation that "the real projectors are the eyes and ears of the audience." Despite all appearances, we do not see and hear a film, we hear/see it-hence the title of Chion's book: Audio-Vision. The difference is the time it takes: the fusion of left and 
right eye into three dimensions takes place instantly because the distance between our eyes does not change. On the other hand the metaphoric distance between the images of a film and the accompanying sounds is-and should be-continuously changing and flexible, and it takes a good number of milliseconds (or sometimes even seconds) for the brain to make the right connections. The image of a door closing accompanied simply by the sound of a door closing is fused almost instantly and produces a relatively flat "audio-vision"; the image of a halfnaked man alone in a Saigon hotel room accompanied by the sound of jungle birds (to use an example from Apocalypse Now) takes longer to fuse but is a more "dimensional" audio-vision when it succeeds.

I might add that, in my own experience, the most successful sounds seem not only to alter what the audience sees but to go further and trigger a kind of conceptual resonance between image and sound: the sound makes us see the image differently, and then this new image makes us hear the sound differently, which in turn makes us see something else in the image, which makes us hear different things in the sound, and so on. This happens rarely enough (I am thinking of certain electronic sounds at the beginning of The Conversation) to be specially prized when it does occur-often by lucky accident, dependent as it is on choosing exactly the right sound at exactly the right metaphoric distance from the image. It has something to do with the time it takes for the audience to "get" the metaphors: not instantaneously, but not much delayed either-like a good joke.

The question remains, in all of this, why we generally perceive the product of the fusion of image and sound - the audio-vision-in terms of the image. In other words, why does King Sight still sit on his throne?

One of Chion's most original observations-the phantom Acousmêtre-depends for its effect on delaying the fusion of sound and image to the extreme, by supplying only the sound-almost always a voice-and withholding the image of the sound's true source until nearly the very end of the film. Only then, when the audience has used its imagination to the fullest, as in a radio play, is the real identity of the source revealed, almost always with an accompanying loss of imagined power: the wizard in The Wizard of $\mathrm{Oz}$ is one of a number of examples cited, along with Hal in 2001 and the mother in Psycho. The Acousmêtre is, for various reasons having to do with our perceptions 
(the disembodied voice seems to come from everywhere and therefore to have no clearly defined limits to its power), a uniquely cinematic device. And yet...

And yet there is an echo here of our earliest experience of the world: the revelation at birth (or soon after) that the song that sang to us from the very dawn of our consciousness in the womb-a song that seemed to come from everywhere and to be part of us before we had any conception of what "us" meant-that this song is the voice of another and that she is now separate from us and we from her. We regret the loss of former unity-some say that our lives are a ceaseless quest to retrieve it - and yet we delight in seeing the face of our mother: the one is the price to be paid for the other.

This earliest, most powerful fusion of sound and image sets the tone for all that are to come. One of the dominant themes of my experience with sound, ever since that first encounter at age ten, has been continual discovery - the exhilaration forty years later of coming upon new features of a landscape that has still not been entirely mapped out. Chion's contributions here and in his previous books combine a serious attempt to discover the true coordinates and features of this continent of sound with the excitement of those early explorers who have forged their own path through the forests and return with tales of wonderful things seen for the first time. For all that Chion pursues the goal of a coherent theory, though, perhaps his theory's greatest attribute is its recognition that within that coherence there is no place for completeness-that there will always be something about sound that "bypasses and surprises us," and that we must never entirely succeed in taming the dancing shadow and the singing soul. 